\title{
Met "Ik geef u onze folder mee" heeft een op de tien nóg geen idee
}

\author{
F. W. M. Schlatmann ${ }^{1}$ I. Hofmeester ${ }^{2}$ M. R. van Balken ${ }^{1}$
}

Published online: 28 July 2016

(C) The Author(s) 2016. This article is available at SpringerLink with Open Access

Samenvatting Door de huidige toename van schriftelijke en digitale informatievoorziening ontstaat een groeiende gezondheidsachterstand bij laaggeletterden, hetgeen verder verergert door het verbergen van het probleem door patiënten en het ontbreken van awareness bij artsen. De consequenties van laaggeletterdheid op zorg- en financieel vlak zijn echter groot: onder andere slechtere (oncologische) uitslagen (tot 40\%) en forse meerkosten (2013: 127 miljoen euro). Bij analyse op de polikliniek Urologie in het Rijnstate middels een gevalideerde vragenlijst, blijkt sprake van laaggeletterdheid bij $11 \%$ van de urologische patiënten. Bewustwording van de incidentie van laaggeletterdheid in de spreekkamer en aanpassing van de informatievoorziening zijn van het grootste belang.

Trefwoorden laaggeletterdheid · health illiteracy · informatievoorziening - gezondheidsachterstand

\section{"Health illiteracy in urological patients: far from being a closed chapter"}

Abstract Because of a strongly increased dependence on (digital) written information, a progressive health gap in people with Low Literacy Skills (LLS) arises, which further increases by the taboo and low awareness of LLS amongst doctors. Consequences of LLS on health results and finances are major: worse (oncological) outcome measures

drs. F. W. M. Schlatmann

fschlatmann@rijnstate.nl

1 afdeling Urologie, Rijnstate, Arnhem, Nederland

2 afdeling Urologie, Isala, Zwolle, Nederland (up to $40 \%$ ) and higher costs; in the Netherlands alone these were estimated to be 127 million Euro per year in 2013. Across sectional questionnaire study in outpatient urology department in the Rijnstate Hospital in the Netherlands with validated questions shows LLS in $11 \%$ of patients. Awareness of the incidence of LLS, adapting information materials and intensifying efforts to reach this audience is of utmost importance.

Keywords health illiteracy - education · low literacy skills $\cdot$ information materials

\section{Introductie}

Het aantal laaggeletterden in Nederland is hoog en naar verwachting neemt geletterdheid ondanks groeiende aandacht zelfs nog wat verder af [1]. Laaggeletterden worden geconfronteerd met een toenemende rol van schriftelijke en digitale informatievoorziening in de zorg. Hierdoor ontstaat voor een steeds grotere groep mensen een informatieachterstand. Deze achterstand neemt verder toe door de heersende taboe en het verbergen van het probleem door de patiënt, maar ook door de lage awareness bij artsen. De consequenties van informatieachterstand in de zorg zijn echter groot: zo zijn er slechtere oncologische resultaten [2] (tot 40\%) en op financieel vlak zijn er forse meerkosten (in 2013 bedroegen deze 127 miljoen euro [3]). Naar schatting lijden 1,3 miljoen Nederlanders ouder dan 16 jaar aan laaggeletterdheid [4]. Doel van ons onderzoek was het vaststellen van het percentage laaggeletterdheid in een representatieve urologische praktijk. 


\section{Methoden}

Gedurende één week werd aan alle patiënten ouder dan 16 jaar die de polikliniek Urologie bezochten $(n=356)$ een gevalideerde en geanonimiseerde vragenlijst (Set of Brief Screening Questions, SBSQ) voorgelegd [5]. Deze werd in de wachtkamer ingevuld en in de spreekkamer ingeleverd bij de arts. De SBSQ bevat drie vragen met vijf keuzemogelijkheden met een Likert-schaal (0-4):

1. Hoe vaak helpt iemand $u$ met het lezen van brieven of folders van uw huisarts, het ziekenhuis of andere zorginstellingen? (nooit, af en toe, soms, vaak, altijd).

2. Hoe zeker bent $\mathrm{u}$ ervan dat $\mathrm{u}$ medische formulieren zelf goed invult? (heel erg, nogal, een beetje, een klein beetje, helemaal niet).

3. Hoe vaak is het moeilijk voor u meer te weten te komen over uw gezondheid, omdat u geschreven informatie niet goed begrijpt? (nooit, af en toe, soms, vaak, altijd).

Hoe hoger de score, hoe beter de geletterdheid. Laaggeletterdheid werd gedefinieerd, zoals beschreven in de literatuur, als een gemiddelde score van 2 of minder. Tevens werd de moedertaal van de patiënt genoteerd.

Omdat er een mogelijke bias zou kunnen ontstaan doordat laaggeletterden de vragenlijst niet inleverden vanwege schaamte of onvermogen om de vragenlijst in te vullen, werd een non-responderanalyse verricht. Hierbij werden de non-responders gerandomiseerd met SPSS en werd $10 \%$ van hen (de schatting van de landelijke incidentie laaggeletterdheid) teruggebeld en werd de SBSQ telefonisch afgenomen.

Beschrijvende analyses werden verricht met behulp van SPSS 22. Incidentie van laaggeletterdheid tussen responders en non-responders werd getoetst met behulp Pearson's chi-kwadraattest, waarbij $p \leq 0,05$ als significant werd beschouwd.

\section{Resultaten}

Van de 356 vragenlijsten werden er 148 geretourneerd (response rate $42 \%$ ). De mediane leeftijd van de respondenten was 67,8 jaar (interkwartielafstand $=53,1-75,1$ ), 81,8\% was man en $93,9 \%$ had Nederlands als moedertaal. Uit de SBSQ bleek dat $12,2 \%(n=18)$ van de respondenten laaggeletterd was (mediane leeftijd $=71,8$ jaar (interkwartielafstand $=66,9-75,9) ;$ man $=66,7 \%$; Nederlands als moedertaal $=88,9 \%)$. De non-reponderanalyse $(n=37)$ toonde een laaggeletterdheid van $10,8 \%(n=4)$ (mediane leeftijd = 79,0 jaar (interkwartielafstand 78,6-87,34); man = $50 \%$; Nederlands als moedertaal $=100 \%$ ). De incidentie van laaggeletterdheid was niet significant verschillend tussen responders en non-responders $(p=.82)$.

\section{Discussie}

Laaggeletterdheid betreft een laag taalniveau, waardoor informatieverwerking lastig is. Hierbij is er sprake van een verminderde woordenschat en een slechter begrip. Laaggeletterdheid is dus niet hetzelfde als analfabetisme, waarbij er een onvermogen tot lezen en schrijven bestaat. Het aantal analfabeten in Nederland wordt geschat op 250.000. De groep laaggeletterden is vele malen groter: circa 1,3 miljoen [1]. Een consequentie van laaggeletterdheid is dat de informatie vanuit de gezondheidszorg minder goed wordt begrepen en het aanleren van vaardigheden lastiger is: de zogenaamde health illiteracy. Het aantal laaggeletterden is in Nederland sinds 1994 onverminderd ruim één miljoen en door de instroom van allochtonen en een toenemende vergrijzing is de prognose voor 2020 dat geletterdheid met $1 \%$ daalt.

Het probleem van laaggeletterdheid voor de urologie is groot. Zo bestaat er bij de patiënt veel onbegrip over veelgebruikte terminologie in de spreekkamer [6]. Begrippen als 'impotentie' en 'erectie' worden door ongeveer $50 \%$ van de laaggeletterden begrepen, maar 'incontinentie' door slechts $5 \%$. Tevens heeft de laaggeletterde minder profijt van de (steeds frequenter aangeboden) keuzehulpen [7]. Door verminderd begrip van ziektekennis en bijkomende alarmsymptomen kan een minder goede behandelkeuze worden gemaakt. Gevolgen hiervan zijn een suboptimaal medicatiegebruik [8] door onduidelijkheid over de inname hiervan, een slechtere (oncologische) uitgangswaarde [9] en een hoger complicatierisico. Bovendien is er bij laaggeletterden een hoger sterfterisico beschreven [2], waarbij een patiënt die slechts basisschoolonderwijs heeft genoten tot $40 \%$ meer risico loopt op sterfte dan een universitair geschoolde. Dit werd onderzocht voor verschillende urologische maligniteiten.

Naast patiëntgebonden problemen van laaggeletterdheid, is laaggeletterdheid ook een probleem voor de uroloog. Zo is het moeilijker om de patiënt een goed begrip bij te brengen van zowel ziekte als behandelopties, wat leidt tot een slechtere informed consent. Tevens zijn er meer no shows op de polikliniek door onbegrip over tijdstip en locatie van de afspraak. Ook is er meer uitval van operaties door onbegrip over het staken van antistolling en het nuchter moeten zijn. In totaal leidt laaggeletterdheid echter tot meer ziekenhuisbezoeken [10], omdat er door een slechtere uitgangssituatie en een verminderd begrip meer contactmomenten plaatsvinden. De totale additionele kosten door laaggeletterdheid zijn 127 miljoen euro per jaar [2]. Dit komt overeen met ongeveer 360 euro per laaggeletterde per jaar [4].

Uit ons onderzoek blijkt dat $11 \%$ van onze patiënten laaggeletterd is. Dit komt redelijk overeen met de schatting in de Nederlandse bevolking van circa 1,3 miljoen laagge- 
letterden. De inschatting is dat de overeenkomst met wat men op andere locaties in Nederland mag verwachten, aannemelijk is, doordat het adherentiegebied van het Rijnstate een grote stad met omliggende dorpen betreft. Daarnaast is er een non-responderanalyse verricht om zo een mogelijke bias van niet-geretourneerde vragenlijsten door laaggeletterden te ondervangen. De betrouwbaarheid van ons onderzoek zou kunnen zijn beïnvloed door de kleine onderzoekspopulatie.

Om aan de informatieachterstand van laaggeletterden tegemoet te komen, kan informatiemateriaal worden aangepast. Zo leiden meer figuratieve folders tot een beter begrip van de inhoud. Gesproken animaties zorgen zelfs voor het verhogen van het kennisniveau van een laaggeletterde naar die van een geletterde [11].

Grote uitdaging blijft echter de bereikbaarheid van de laaggeletterde patiënt. Het probleem van het verminderd begrip van taal is dat het heel lastig is om hen met tekst te bereiken, hetzij schriftelijk met bijvoorbeeld folders of posters, hetzij via internetsites. Tevens heerst er een gêne onder patiënten en kunnen zij hun probleem goed verhullen. Niet op de laatste plaats is er echter sprake van een lage awareness bij artsen over laaggeletterdheid en de incidentie hiervan. Wij hopen dat dit artikel bijdraagt aan een verbetering van die awareness.

\section{Conclusie}

Op de polikliniek Urologie van het Rijnstate is ongeveer $11 \%$ van de patiënten laaggeletterd. Verhogen van awareness van artsen is van belang, evenals een gestructureerde aanpak en de ontwikkeling van patiëntenmateriaal dat is gericht op deze specifieke populatie.

Open Access This article is distributed under the terms of the Creative Commons Attribution 4.0 International License (http:// creativecommons.org/licenses/by/4.0/), which permits unrestricted use, distribution, and reproduction in any medium, provided you give appropriate credit to the original author(s) and the source, provide a link to the Creative Commons license, and indicate if changes were made.

\section{Literatuur}

1. Expertisecentrum Beroepsonderwijs. Laaggeletterdheid in Nederland. http://www.piaac.nl/_images/user/20131008093450ecbo_ Publicatie_laaggeletterdheid_in_Nederland_web.pdf (Gecreëerd: September 2011). Geconsulteerd: 20. Jan 2016.

2. Hussein SK, Lenner P, Sundquist J, et al. Influence of education level on cancer survival in Sweden. Ann Oncol. 2008;19(1):156-62.

3. Nederlands Instituut Voor onderzoek van de EersteLijnsgezondheidszorg (NIVEL). Laaggeletterde heeft meer kans op een slechte gezondheid. http://www.nivel.nl/nieuws/laaggeletterde-heeftmeer-kans-op-een-slechte-gezondheid (Gecreëerd: 30. Jun 2015). Geconsulteerd: 20. Jan 2016.

4. Stichting Lezen en Schrijven. Feiten 2015. http://www. lezenenschrijven.nl/feiten. Geconsulteerd: 20. Jan 2016.

5. Franssen MP, Van Schaik TM, Twickler TB, et al. Applicability of internationally available health literacy measures in the Netherlands. J Health Commun. 2011;16(3):134-50.

6. Kilbridge KL, Fraser G, Krahn M, et al. Lack of comprehension of common prostate cancer terms in an underserved population. J Clin Oncol. 2009;27(12):2015-21.

7. Kripalani S, Sharma J, Justice E, et al. Low-literacy interventions to promote discussion of prostate cancer: arandomized controlled trial. Am J Prev Med. 2007;33(2):83-90.

8. Koninklijke Nederlandse maatschappij ter bevordering der pharmacie (KNMP). Laaggeletterdheid en medicatiegebruik 2016. https:// www.knmp.nl/patientenzorg/laaggeletterdheid. Geconsulteerd: 20. Jan 2016.

9. Wolf MS, Knight SJ, Lyons EA, et al. Literacy, race, and PSA level among low-income men newly diagnosed with prostate cancer. Urology. 2006;68(1):89-93.

10. HLS-EU Consortium. Comparative Report of Health LIteracy in Eight EU Member States. The European Health Literacy Survey HLS-EU 2012. http://www.health-literacy.eu.

11. Meppelink CS, Weert JC van, Haven CJ, Smit EG. The Effectiveness of Health Animations in Audiences With Different Health Literacy Levels: An Experimental Study. J Med Internet Res. 2015;17(1):e11.

drs. F.W.M. Schlatmann uroloog i.o.

drs. I. Hofmeester uroloog i.o.

dr. M.R. van Balken uroloog 